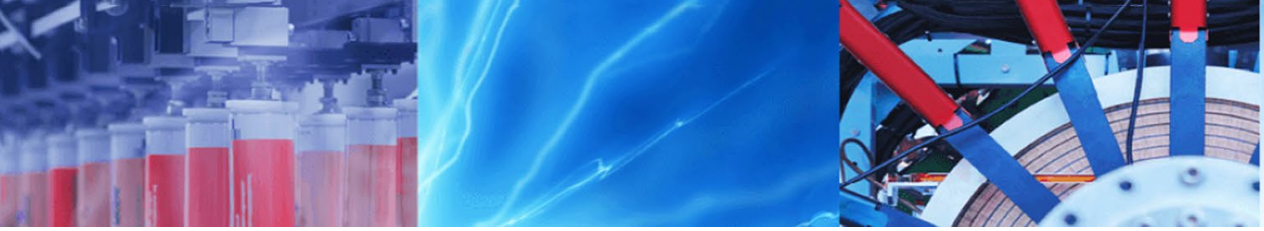

Research Article

\title{
Chitosan biopolymer based nanocomposite hydrogels for removal of methylene blue dye
}

\author{
Ghada A. Mahmoud ${ }^{1} \cdot$ Asmaa Sayed $^{1}$ (1) $\cdot$ Maryan Thabit $^{2} \cdot$ Gehan Safwat $^{2}$
}

Received: 30 January 2020 / Accepted: 15 April 2020 / Published online: 25 April 2020

(c) Springer Nature Switzerland AG 2020

\begin{abstract}
Nanocomposite hydrogels were synthesized by ${ }$-radiation-induced copolymerization and crosslinking of Chitosan biopolymer (CS), acrylic acid (AAc) and $\mathrm{TiO}_{2}$ nanoparticles (CS-PAAc/TiO ${ }_{2}$ ). The structure, morphology, and properties of the nanocomposites were investigated using Fourier-transform infrared spectroscopy, X-Ray Diffraction, Scanning electron microscopy, Transmission electron microscopy, and thermogravimetric analysis techniques. The nanocomposites hydrogel was used for the removal of methylene blue dye (MB) from wastewater. It was found that the presence of $\mathrm{TiO}_{2}$ in the copolymeric matrix enhances the adsorption by increasing the physical interaction between the dye molecules and the adsorbent surface. The removal percentage increases with the increase in $\mathrm{pH}$ of the medium of all investigated samples and the maximum value is obtained at the solution $\mathrm{pH}$ is 10 . The maximum adsorbent dosage for CS-PAAC/ $\mathrm{TiO}_{2}$ nanocomposites is $0.20 \mathrm{~g}$ and for CS-PAAc hydrogel is $0.15 \mathrm{~g}$ per liter of the adsorbate. This study revealed that the loading of $\mathrm{TiO}_{2}$ nanoparticles into the polymeric matrix of CS-PAAc does a remarkable increase in the removal parentage of $\mathrm{MB}$ dye from its aqueous solution.
\end{abstract}

Keywords Gamma radiation $\cdot$ Nanocomposite $\cdot$ Chitosan $\cdot \mathrm{TiO}_{2} \cdot$ Dye removal

\section{Introduction}

The effluent dye industry has caused severe hazards to the environment and biology due to its complex structure and chromogenic functional groups [1-3]. Among many pollutants that the mill discharges millions of gallons into the water contain naphthol, vat dyes, sulfur, nitrates, acetic acid, chromium compounds and heavy metal ions like arsenic, lead, cadmium, copper, and many other pollutants [4-6]. Most of these contaminants are hydrocarbon-based softeners, formaldehyde-based dye fixing agents and nonbiodegradable dyeing chemicals $[1,2,6]$. Methylene blue dye $(\mathrm{MB})$ is harm to the respiratory system and skin. It can cause vomiting and even cancer for living organisms [4]. $\mathrm{MB}$ absorbs light, and it affects the growth of the aquatic organisms [5]. Moreover, the aromatic structure is hardly biodegradable which means the remaining of $M B$ for a long time if there is no adopting method for treatment [7]. Various physicochemical techniques such as adsorption, photodegradation, and membrane separation have been applied to treat the dye effluents [8]. The ideal material for efficient adsorption should possess the properties of porosity, high surface area, and physicochemical stability [9]. Bio-based adsorbents are considered one of the most promising materials in water treatment [10].

One of the most interesting materials for scientists is Chitosan (CS). It is a biodegradable, renewable, and inexpensive natural polymer $[11,12]$. It has many environmentally friendly qualities and has high efficiency in water purification $[13,14]$. Chitosan is used for the

$\triangle$ Asmaa Sayed, asmaasayedncrrt@gmail.com | ${ }^{1}$ Polymer Chemistry Department, National Center for Radiation Research and Technology, Atomic Energy Authority, P.O. Box 29, Nasr City, Cairo, Egypt. ${ }^{2}$ Faculty of Biotechnology, October University for Modern Science and Art (MSA), 6th October City, Egypt. 
removal of dyes and metals $[15,16]$ as it has active adsorption sites like amino $\left(-\mathrm{NH}_{2}\right)$ and hydroxyl $(-\mathrm{OH})$ functional groups and metals. However, it has some disadvantages for industrial applications [3], wastewater technologies, such as the too soft structure, which creates problems [17-19], its high solubility in the organic solvent, high swelling percent in water, low mechanical strength, and low surface area [20]. Many studies have been applied to improve CS properties and efficiency [21-23]. The combination of inorganic [24] and polymeric materials [25] is a successful strategy for the improvement of the restricted properties and developing new properties by introducing new functional groups that can be enhancing the ability of dye-binding [26-28]. Also improving the chemical stability of chitosan toward the acidic environment and reduce its the hydrophobicity chemical cross-linking reaction used [29]. Graft polymerization of vinyl monomers onto chitosan using gamma irradiation have been reported [30] for examples butyl acrylate onto chitosan [31], it was revealed that grafting percentage increased as the monomer concentration and the total irradiation dose were increased. Radiation grafting of acrylamide and maleic acid on chitosan and its effective application for removal of Co(II) from aqueous solutions has been studied by Saleh et al.; [32] it was found that chitosan-P(acrylamide) and chitosan- $\mathrm{P}$ (maleic acid) show high sorption capacity toward $\mathrm{Co}$ (II) as. $150 \mathrm{mg} / \mathrm{g}$ and $421 \mathrm{mg} / \mathrm{g}$, respectively, that makes them potential sorbents of $\mathrm{Co}$ (II) for wastewater treatment.

In this study, (CS- PAAc/ $\mathrm{TiO}_{2}$ ) nanocomposite hydrogel was prepared using the gamma irradiation technique. This technique has the advantage of liberty from toxic impurities such as crosslinking agents and initiators [33, 34]. Characterization and properties the prepared nanocomposites were studied using different techniques. The influence of $\mathrm{TiO}_{2}$ nanoparticle content on the adsorption was studied towards methyl blue dye (MB). The effect of different parameters was studied to estimate the best condition for adsorption of methyl blue dye (MB) dye that was included; $\mathrm{pH}$ of dye solution; adsorbent dose and temperature of the feed solution.

\section{Materials and methods}

Chitosan (CS) has average molecular weight 100.000-300.000 (Acros, Belgium), acrylic acid (AAC) of purity $99.9 \%$ (Aldrich) and titanium dioxide nanoparticle $\left(\mathrm{TiO}_{2}\right.$ ) of powder size $15 \pm 3 \mathrm{~nm}$ (nano-gate; Egypt) were used without further purification. Other chemicals, such as buffers were purchased from El-Nasr Co. for Chemical Industries, Egypt and used without further purification.

\subsection{Preparation of CS-PAAc hydrogel}

CS-PAAc hydrogels were prepared by adding AAc to CS in different copolymer composition wt.\%, to obtain a solution of total concentration $20 \mathrm{wt} . \%$. The solution was transferred into a glass tube to be irradiated by $\gamma$-rays from Co-60 source at radiation dose of $30 \mathrm{kGy}$. The hydrogels were obtained in a long cylindrical shape and were cut into small pieces. All samples were washed in excess water to remove the unreacted component then dried in air to constant weight.

\subsection{Preparation of CS-PAAC/TiO 2 nanocomposite}

A solution of CS-PAAc of equal ratio was prepared as mentioned above and different content of $\mathrm{TiO}_{2}, 0.0,1.0,2.0$ \& $3.0 \mathrm{wt} . \%$ of the total polymer concentration, was added to the solution. The mixtures were sonicated in a bath sonicator for $15 \mathrm{~min}$ to obtain homogenous solutions. The solutions were transferred into small glass vials and were subjected to ${ }^{60} \mathrm{Co}$-gamma rays at irradiation dose of $30 \mathrm{kGy}$. After that, the above steps of preparation CS-PAAc hydrogel were followed.

\subsection{Gamma irradiation}

Irradiation to the required doses was carried out in the cobalt-60 $\left({ }^{60} \mathrm{Co}\right)$ gamma cell (India) at a dose rate range from 1.77 to $2.23 \mathrm{kGy} / \mathrm{min}$ in air. This source was installed at the National Center for Radiation Research and Technology (NCRRT).

\subsection{FTIR spectroscopy measurement}

The infrared spectra were investigated by FTIR spectrophotometer, Spectrum One, Perkin Elmer, USA, over the range of $4000-400 \mathrm{~cm}^{-1}$.

\subsection{X-ray diffraction analysis (XRD)}

XRD analysis was carried out using a Shimadzu Diffractometer D6000 series Kyoto, Japan. (30 mA and 40 kv) at Cu Ka $(\lambda=1.54 \AA)$ radiation at room temperature in a $2 \theta$ range of 4-90 scan speed $8 \mathrm{deg} / \mathrm{min}$. The average particle size was also calculated using the Scherer formula.

$L_{\theta}=\frac{k \lambda}{\beta \cos \theta}$ 
where, $L_{\theta}$ is average grain size of formed crystallite and $\lambda$ $(1.54 \AA)$ is the wavelength of used $X$-ray. $\beta$ denotes the full width at half maximum (FWHM) for corresponding diffraction peak and $\theta$ is diffraction angle. $k$ is constant (K:0.9-1).

\subsection{Scanning electron microscope (SEM)}

Scanning Electron Microscope analysis (SEM) Surface of the samples was investigated by Jasco JSM-5200 scanning electron microscope (SEM), Japan with voltage accelerated at $25 \mathrm{kV}$ after gold deposition in vacuum for $3 \mathrm{~min}$.

\subsection{Transmission electron microscopy (TEM)}

The morphology of the nanocomposite was observed using transmission electron microscope (TEM) (JEOL-JEM 1400CX ELECTRON MICROSCOPE, Japan,) at acceleration voltage $80 \mathrm{kV}$. The nanocomposite sample was prepared by grinding carefully, mixed with acetone, and accompanied by a sonication process. A drop of the solution was deposited on a microgrid, to prevent the high-voltage electron beam from damaging the sample; the chamber of the sample inside the device was placed in a bath of liquid nitrogen to stabilize the temperature.

\subsection{Thermal properties}

Thermal Gravimetric Analysis (TGA) and differential Thermal Analysis DTA. The thermogravimetric analysis (TGA) was performed by using TGA-30 (Shimadzu, Japan) at a heating rate of $10^{\circ} \mathrm{C} / \mathrm{min}$ under the nitrogen atmosphere in the temperature range from room temperature up to $600^{\circ} \mathrm{C}$. The relative thermal stability of the samples was evaluated in terms of decomposition temperature.

\subsection{Swelling properties}

CS-PAAc hydrogels and CS-PAAc/ $\mathrm{TiO}_{2}$ nanocomposite hydrogels of known weights were immersed in distilled water at definite interval times until the equilibrium. The swollen samples were re-weighed after the excess surface water was removed immediately with a filter paper. The degree of swelling was determined according to the following equation:

Degree of Swelling $(\%)=\frac{W_{t}-W_{d}}{W_{d}} \times 100$

where $W_{t}$ is the weight of the sample after swelling at time $t$ and $W_{d}$ is initial of dry sample.

\subsection{Point of zero charge}

The $\mathrm{pH}$ that the charge of the adsorbent surface is zero has known as the zero point of charge (pHZPC). Zeropoint charge $\mathrm{pH}$ of CS-PAAc/ $\mathrm{TiO}_{2}$ (3.0 wt.\%) was determined by the $\mathrm{pH}$ drift method as follows [25]:25 ml of $0.01 \mathrm{M} \mathrm{NaCl}$ solutions were poured into the beakers. The $\mathrm{pH}$ was adjusted $2,4,6,8,10$, and 12 by adding $0.1 \mathrm{M}$ $\mathrm{HCl}$ or $0.1 \mathrm{M} \mathrm{NaOH} .0 .1 \mathrm{~g}$ of adsorbent was then added to each beaker, and the beakers were agitated for $72 \mathrm{~h}$ at room temperature. Finally, the $\mathrm{pH}$ of solutions was measured, and the final $\mathrm{pH}$ was plotted against the initial $\mathrm{pH}$. The zero-point charge $\mathrm{pH}$ is the point of intersection of the resulting curve.

\subsection{Adsorption study}

Batch adsorption experiments were carried out at different temperatures; 25,35 , and $50{ }^{\circ} \mathrm{C}$. Exactly $20 \mathrm{ml}$ of dye solution of known initial concentration $(20 \mathrm{mg} / \mathrm{L})$ at adjusted $\mathrm{pH}$ was shaken at a certain agitation speed of $250 \mathrm{rpm}$ of a known dose of dried sample for $24 \mathrm{~h}$.

The absorption capacity $\left(\mathrm{Q}_{\mathrm{e}}, \mathrm{mg} \cdot \mathrm{g}^{-1}\right)$ and $\mathrm{MB}$ removal percent were calculated using the following equation:

$Q_{e}=\frac{\left(C_{0}-C_{e}\right) V}{m}$

MB Removal $(\%)=\frac{C_{0}-C_{e}}{C_{0}} \times 100$

where, $C_{0}$ and $C_{e}$ (both in $\mathrm{mg} / \mathrm{L}$ ) are the initial dye concentration and the dye concentration at equilibrium, respectively. $V$ is the initial solution volume (L); and $m$ is the adsorbent dry weight (g). MB dye concentration was calculated using a UV/VIS spectrometer, model UV-Jasco $\mathrm{V}-530$ made by Japan at $\lambda_{\max }$ of $664 \mathrm{~nm}$ with a quartz cell of $1.0 \mathrm{~cm}$ optical length.

\section{Results and discussion}

\subsection{FTIR spectroscopy}

The radiation-induced copolymerization mechanism of acrylic acid onto chitosan is shown in Scheme 1. Infrared spectroscopy analysis is an important tool to confirm the occurrence of the functional groups of the prepared hydrogel.

Figure 1 explains the FTIR spectra of CS-PAAc hydrogel and CS-PAAC/TiO 2 (3.0 wt.\%) nanocomposite hydrogel. For CS-PAAC hydrogel, there is broadband that 


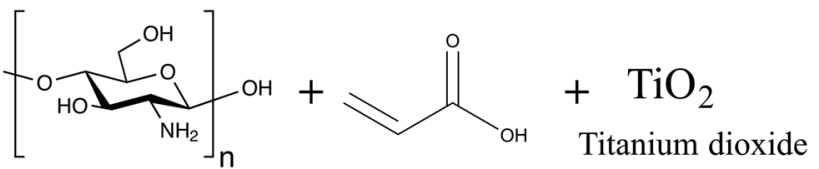

Chitosan

Acrylic acid

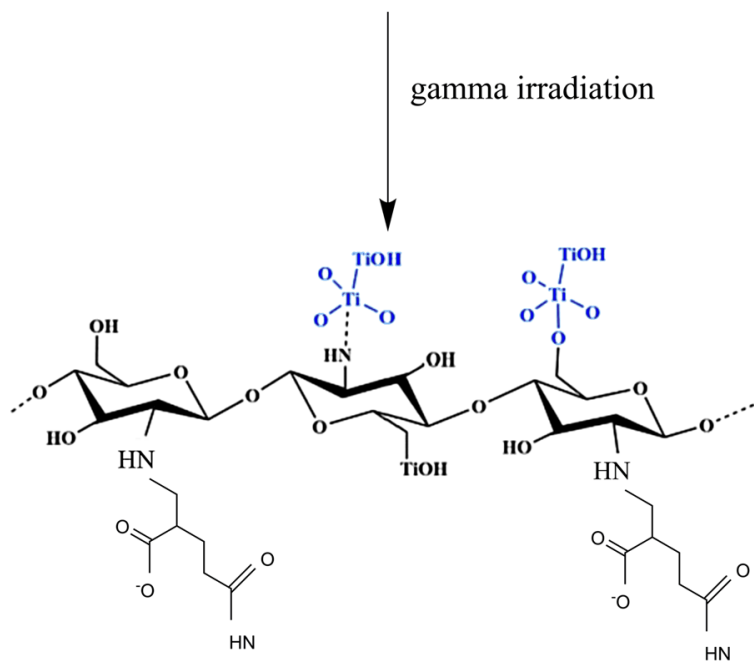

Scheme 1 Synthesis of CS-PAAc/TiO ${ }_{2}$ nanocomposite hydrogel

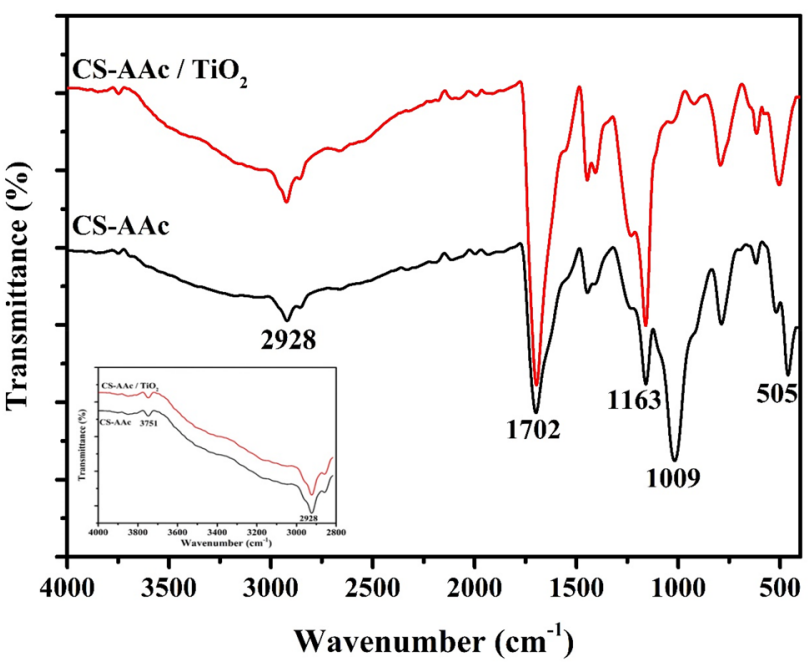

Fig. 1 FTIR spectra of CS-PAAc hydrogel and CS-PAAC/TiO ${ }_{2}$ nanocomposite hydrogel; $\mathrm{TiO}_{2}$ content 3.0 wt.\%

appears in the range of $3678-3003 \mathrm{~cm}^{-1}$ due to $\mathrm{O}-\mathrm{H}$ and $\mathrm{N}-\mathrm{H}$ bands of AAc and CS which overlapped with the stretching band of $\mathrm{C}-\mathrm{H}$ group at $2928 \mathrm{~cm}^{-1}$. The band at $1702 \mathrm{~cm}^{-1}$ corresponds to the $\mathrm{C}=\mathrm{O}$ of the carbonyl group and amide $\mathrm{I}$. The band at $1590 \mathrm{~cm}^{-1}$ due to the $\mathrm{N}-\mathrm{H}$ deformation of the amino group (amine II) [33]. For CS-PAAc/ $/ \mathrm{TiO}_{2}$ nanocomposite a new peak was observed at $505 \mathrm{~cm}^{-1}$ due to Ti-O-Ti vibration [35].

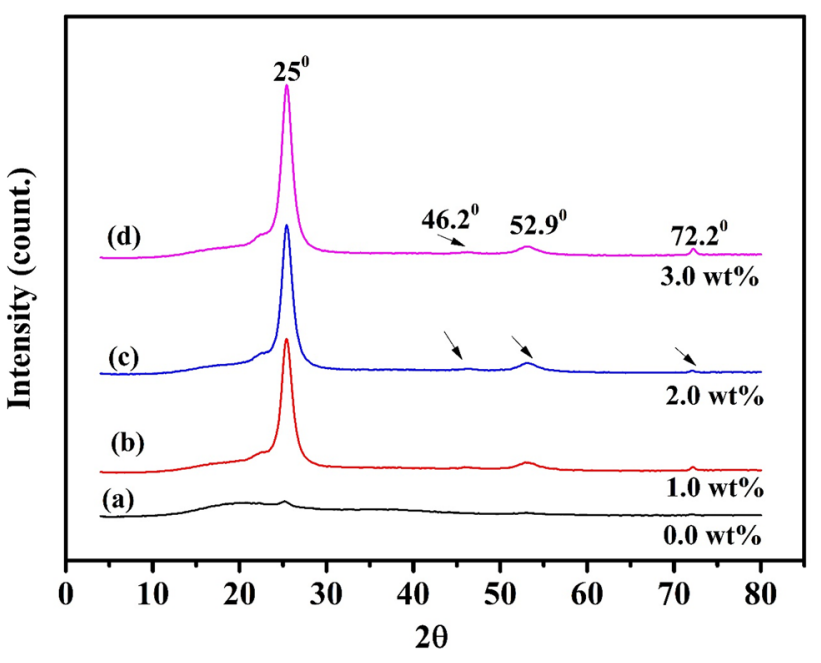

Fig. 2 XRD patterns of CS-PAAC/TiO 2 nanocomposites of different $\mathrm{TiO}_{2}$ content

\subsection{X-ray diffraction (XRD)}

XRD diffractograms of CS-PAAC/TiO 2 nanocomposite hydrogels were investigated in a $2 \theta$ range of $4^{\circ}-90^{\circ}$ and the results are shown in Fig. 2 . In the pattern of CS-PAAC hydrogel $\left(0.0 \% \mathrm{TiO}_{2}\right)$, a broad peak was observed at $2 \theta=20^{\circ}$ due to the CS-PAAc copolymer hydrogel network and confirmed the formation of an amorphous phase in the hydrogel [34]. In CS-PAAc/ $/ \mathrm{TO}_{2}$ nanocomposite hydrogels patterns, sharp peaks appear at $2 \theta=25^{\circ}$ compared with the XRD pattern of the CS-PAAc hydrogel. The intensity of peaks increases as $\mathrm{TiO}_{2}$ content increases. Moreover, the presence of low-intensity diffraction peaks at $2 \theta$ values of about $46.2^{\circ}, 52.9^{\circ}$, and $72.2^{\circ}$ assigned to $\mathrm{TiO}_{2}$ nanoparticles. These diffraction peaks confirmed the presence of crystalline $\mathrm{TiO}_{2}$ nanoparticles in the nanocomposite hydrogels [36]. The average particle size of $\mathrm{TiO}_{2}$ nanoparticles was calculated by the Scherrer equation (Eq. 1). It is estimated as; $5.8,5.7$, and $5.9 \mathrm{~nm}$ for $1.0,2.0$, and $3.0 \mathrm{wt} \% \mathrm{TiO}_{2}$ content; respectively in the CS-PAAc/ $\mathrm{TiO}_{2}$ nanocomposite hydrogels.

\subsection{Thermal properties}

Thermogravimetric analysis (TGA) and differential thermal analysis (DTA) were evaluated as shown in Fig. 3. TGA determines the changes in weight as a function of temperature [37]. The TGA results [Fig. 3a] seem similar thermal behaviors and maximum thermal temperature in each stage of all investigated samples. In general, the TG curves resolved four main decomposition stages. The first decomposition stage in the range of $\sim 50-180^{\circ} \mathrm{C}$ due to the evaporation of the physically bonded water. This stage 
Fig. 3 a TGA and b DTA analysis of CS-PAAc hydrogel and $\mathrm{CS}-\mathrm{PAAc} / \mathrm{TiO}_{2}$ nanocomposites hydrogel; $\mathrm{TiO}_{2}$ content $(0.0,1.0$, $2.0 \& 3.0$ wt.\%)

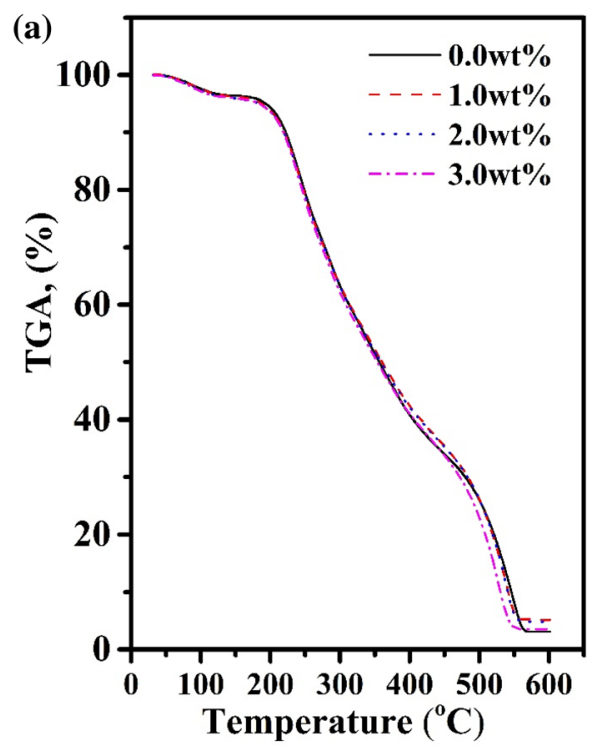

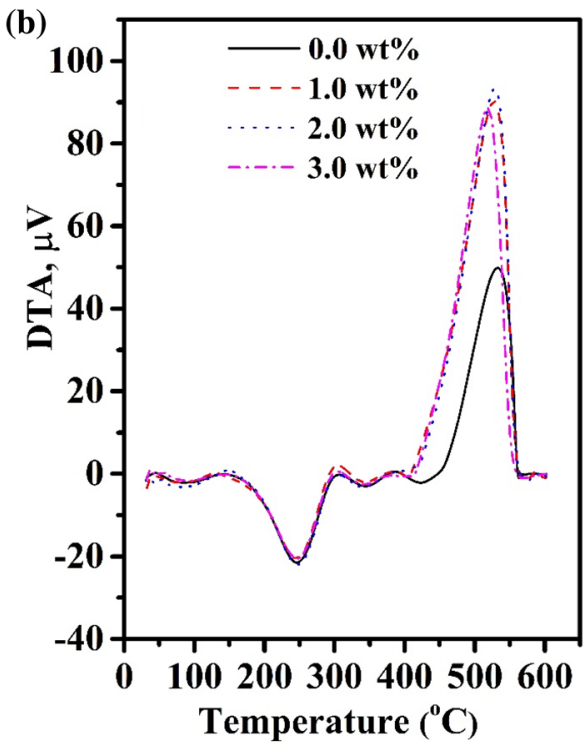

accompanies by an endothermic peak centered at $121^{\circ} \mathrm{C}$ [Fig. 3b]. The second decomposition stage in the range of $180-293^{\circ} \mathrm{C}$ due to the destruction of the side groups and vaporization of voltaic compounds [38]. A broad endothermic peak centered at $253^{\circ} \mathrm{C}$ accompanies this stage. The third decomposition stage occurs in the range of $293-423^{\circ} \mathrm{C}$ due to due to thermal degradation of the backbone polymeric chains and accompanies by endothermic peak centered at $354^{\circ} \mathrm{C}$. The last decomposition stage was detected in the range of $423-558^{\circ} \mathrm{C}$ accompanies with a sharp exothermic peak [Fig. 3b] corresponds to the transformation of the $\mathrm{TiO}_{2}$ nanoparticles phase.

\subsection{The swelling properties}

The swelling of the polymeric material is important in several aspects. Water molecules may act as plasticizers relaxing interaction between the polymeric chains. Moreover, it may have a dramatic change in the permeability properties, especially in the hydrophilic polymers. Figure 4a represents the effect of CS-AAc composition on the swelling percentage. It can be seen that the swelling percentage enhances as the content of AAC is increased. It was reported that as the polymer chain backbone is built using a hydrophilic type monomer, here is (AAc), the water uptake may increase [39]. Figure $4 \mathrm{~b}$ shows the effect of $\mathrm{TiO}_{2}$ content on the
Fig. 4 a Effect of CS-AAC composition on the swelling percentage of CS-AAc hydrogel; $\mathbf{b}$ Effect of $\mathrm{TiO}_{2}$ content on the swelling percentage of $\mathrm{CS}-\mathrm{AAc} / \mathrm{TiO}_{2}$ nanocomposite hydrogel, CS: AAC (50:50 wt.\%)

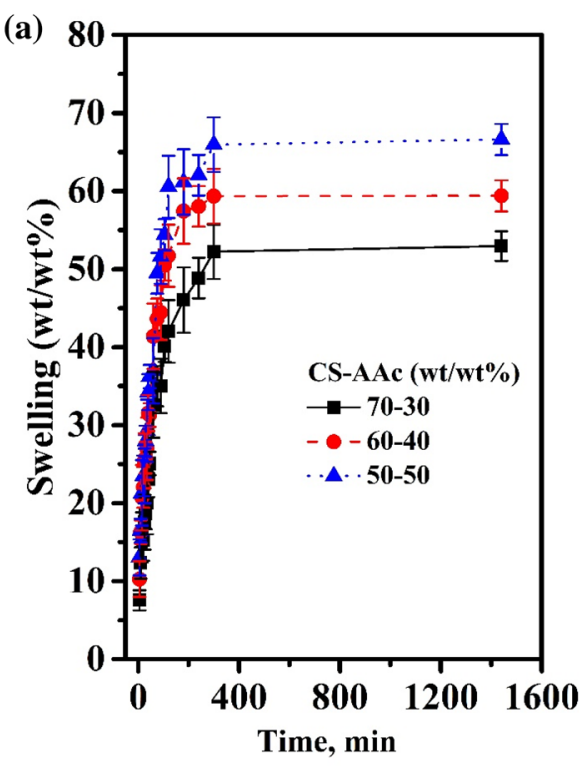

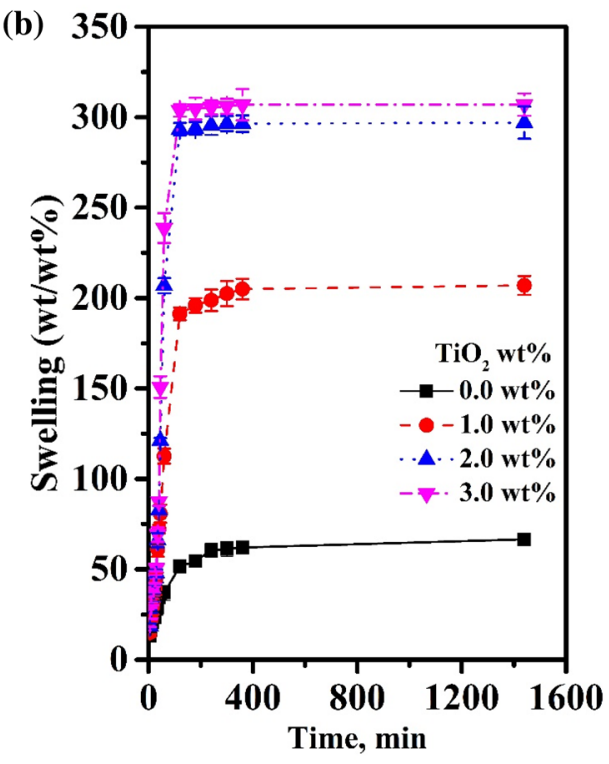

SN Applied Sciences 
swelling percentage of $\mathrm{CS}-\mathrm{PAAC} / \mathrm{TiO}_{2}$ nanocomposite hydrogels. It can be noted that the swelling percentage increases with the increase of $\mathrm{TiO}_{2}$ content in the matrix. The swelling percentage enhances nearly fourth times by adding $1 \mathrm{wt} . \% \mathrm{TiO}_{2}$ nanoparticle in the nanocomposite hydrogel compared with CS-PAAc hydrogel. The increase of $\mathrm{TiO}_{2}$ content in the nanocomposite matrix may reduce the crosslink density. Where a large free volume is available in the polymeric network consequently, more water can be absorbed [40].

\subsection{Surface morphology}

The surface morphology of the prepared CS-PAAc hydrogel and CS-PAAC/TiO 2 nanocomposites hydrogel was examined by SEM as shown in Fig. 5. The SEM image of
CS-PAAc hydrogel [Fig. 5a] appears as a net-like structure with pores due to the hydrophilicity of both $C S$ and PAAC, that have a great affinity to swell in water. CS-PAAC hydrogel morphology is changed drastically when loaded with $\mathrm{TiO}_{2}$ [Fig. 5b]. The surface morphological structure of CS-PAAc/ $/ \mathrm{TiO}_{2}$ nanocomposite, 3 wt. $\%$ of $\mathrm{TiO}_{2}$, appears as a compact surface with very large pores and this result illustrates the increase of the swelling percentage in the presence of $\mathrm{TiO}_{2}$ nanoparticle.

Figure $5 \mathrm{c}$ shows the TEM image of CS-PAAc/ $/ \mathrm{TiO}_{2}$ nanocomposite hydrogel. It is clear that $\mathrm{TiO}_{2}$ nanoparticles appears as black irregular spherical particles. The particle size is in the range of $32-59 \mathrm{~nm}$. This means there is some agglomerations where the calculated particle size by the Scherrer equation is about $6 \mathrm{~nm}$.
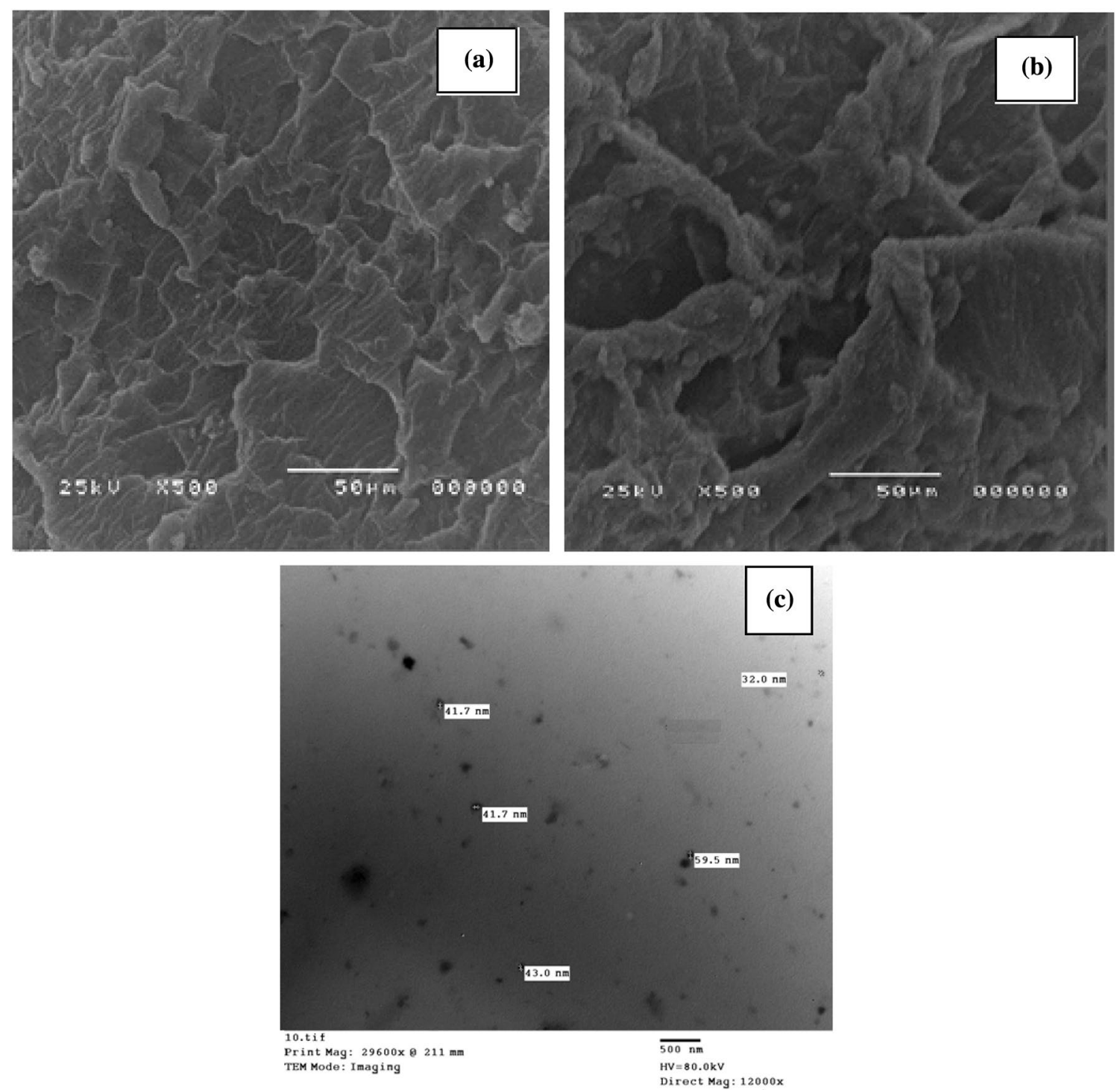

Fig. 5 a SEM of CS-PAAc hydrogel; b SEM of CS-PAAc/TiO 2 nanocompositeand c TEM of CS-PAAc/TiO ${ }_{2}$ nanocomposites; $\mathrm{TiO}_{2}$ content 3 wt.\% 


\subsection{Adsorption study}

The adsorption characteristics of the prepared CS-PAAc/ $\mathrm{TiO}_{2}$ nanocomposites towards methylene blue dye (MB) were examined. Furthermore, the adsorption behavior of CS-PAAc hydrogel ( $\mathrm{TiO}_{2} ; 0$ wt.\%) was also evaluated to know the influence of the presence of $\mathrm{TiO}_{2}$ nanoparticles in the copolymeric matrix. The factors affect the adsorption behavior such as $\mathrm{pH}$, adsorbent dose, and temperature were studied.

As it is clear in Fig. 6a, CS-PAAc hydrogel and CS-PAAc/ $\mathrm{TiO}_{2}$ nanocomposite hydrogel have negatively charge surface in $\mathrm{pH}$ range 2 to 12 . It has been reported that, at $\mathrm{pH}$ less than $\mathrm{pHzpc}$, due to the presence of the high concentration of $\mathrm{H}^{+}$ions in the environment, the surface charge of adsorbent is positive [41] while at $\mathrm{pH}$ greater than $\mathrm{pHpzc}$ the surface is negatively charged. The acidic character of CS-AAc/TiO 2 surface is attributted to the Acrylic acid $\mathrm{COOH}$ - and the acidic feature of titanium dioxide.

The influence of $\mathrm{pH}$ of the medium on the removal percentage of $\mathrm{MB}$ by CS-PAAc/ $\mathrm{TiO}_{2}$ nanocomposites was examined over $\mathrm{pH}$ range values between 2.0 through 10.5 and the results are shown in Fig. $6 \mathrm{~b}$. It was found that the removal percentage increases with the increase in $\mathrm{pH}$ of the medium of all investigated samples and the maximum value are got at $\mathrm{pH}$ 10.5. It is well known that the extent of adsorption is highly varied according to the adsorbent functional groups [42]. MB is cationic dye. At low pH values, the amino group of $\mathrm{CS}$ is protonated, the existence of partially positive charges on the adsorbent reduces the removal percentage by the electrostatic reparation between them and the cationic dye molecules. As the $\mathrm{pH}$ value increases over the pKa of $-\mathrm{COOH}$ which is approximately 4.6 [43] the carboxylic acid groups are ionized. An electrostatic attraction between the positively charged cationic dye and the negatively charged carboxylate anion is done which responsible for enhancing the removal percentage. On the other hand, it can be noted that CS-PAAC hydrogel $\left(\mathrm{TiO}_{2} ; 0 \mathrm{wt}\right)$ has the lowest removal percentage. An enhancement in the removal percentage was observed by using CS-PAAC/TiO 2 nanocomposites. However, no remarkable change in the adsorption was detected by increasing the $\mathrm{TiO}_{2}$ content in the nanocomposite matrix. The presence of $\mathrm{TiO}_{2}$ in the copolymeric matrix enhances the adsorption by increasing the physical interaction between the dye molecules and the adsorbent surface. As mentioned before in the examination of the surface morphology by SEM, the surface of the nanocomposite has very large pores compared with CS-PAAc hydrogel, Fig. $5 \mathrm{a}$, b. The large pores permit the possibility of the connection between the adsorbent surface and MB molecules through the large surface area.

The influence of the adsorbent dosage on the removal percentage is shown in Fig. 7. It can be obtained that the removal percentage values increase with increasing the dosage of the sorbent from 0.05 to $0.15 \mathrm{~g}$. Above this value a decrease in adsorption was observed for CS-PAAC hydrogel. In addition, a little increase in adsorption was done at $0.2 \mathrm{~g}$ of the two investigated nanocomposites. The maximum adsorbent dosage for the investigated $\mathrm{CS}-\mathrm{PAAc} / \mathrm{TiO}_{2}$ nanocomposites is $0.20 \mathrm{~g}$ per liter of adsorbate and for CS-PAAc hydrogel is $0.15 \mathrm{~g}$ per liter

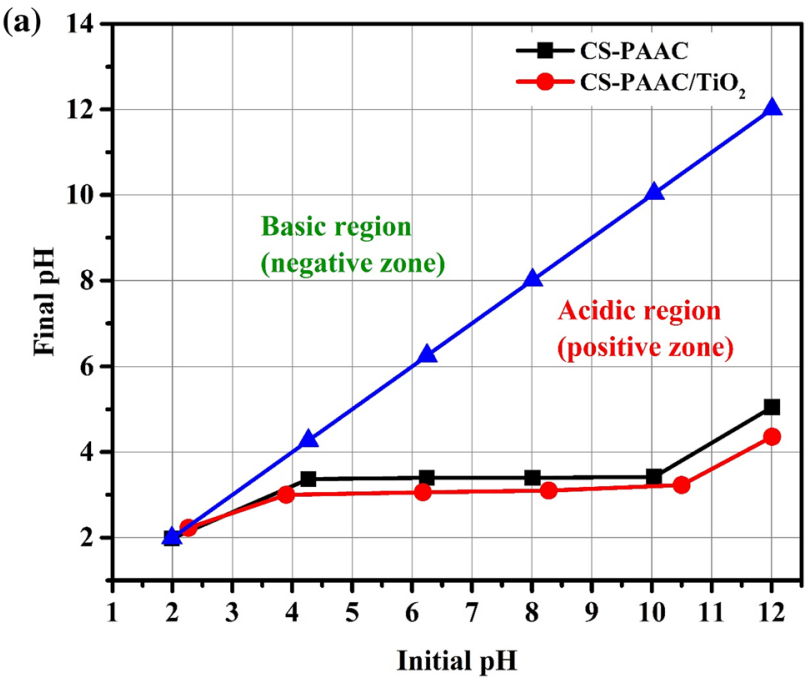

Fig. 6 a The pH drift method for CS-PAAc and CS-PAAc/TiO ${ }_{2}$ nanocomposite; blue line indicates that $\left(\mathrm{pH}_{\mathrm{i}}\right)=\left(\mathrm{pH}_{\mathrm{f}}\right)$. $\mathbf{b}$ The effect of $\mathrm{pH}$ on the removal percentage of $\mathrm{MB}$ dye by $\mathrm{CS}-\mathrm{PAAC} / \mathrm{TiO}_{2}$ nanocom-

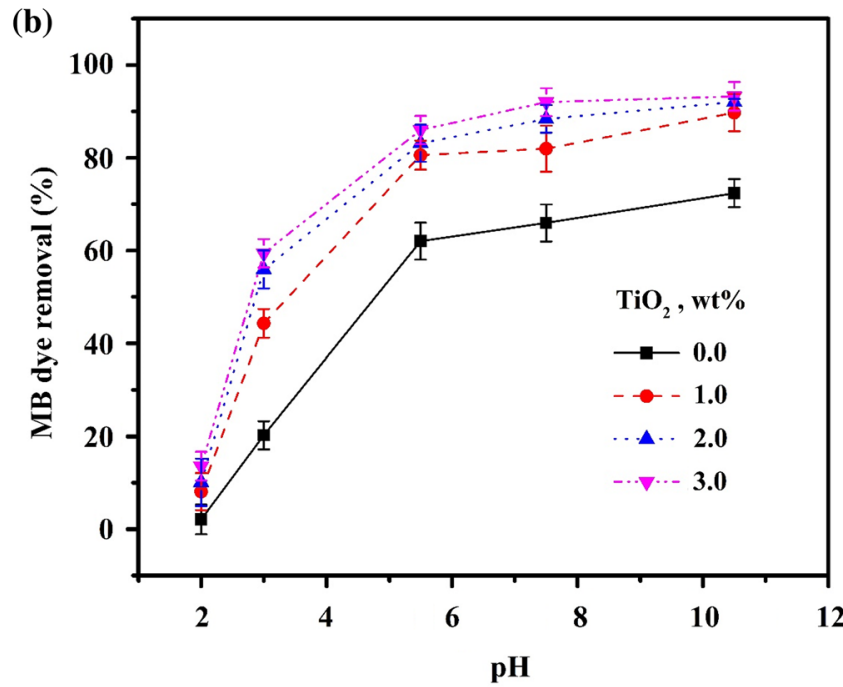

posites at ambient temperature, initial dye concentration; $20 \mathrm{mg} / \mathrm{L}$ and contact time; $24 \mathrm{~h}$ 


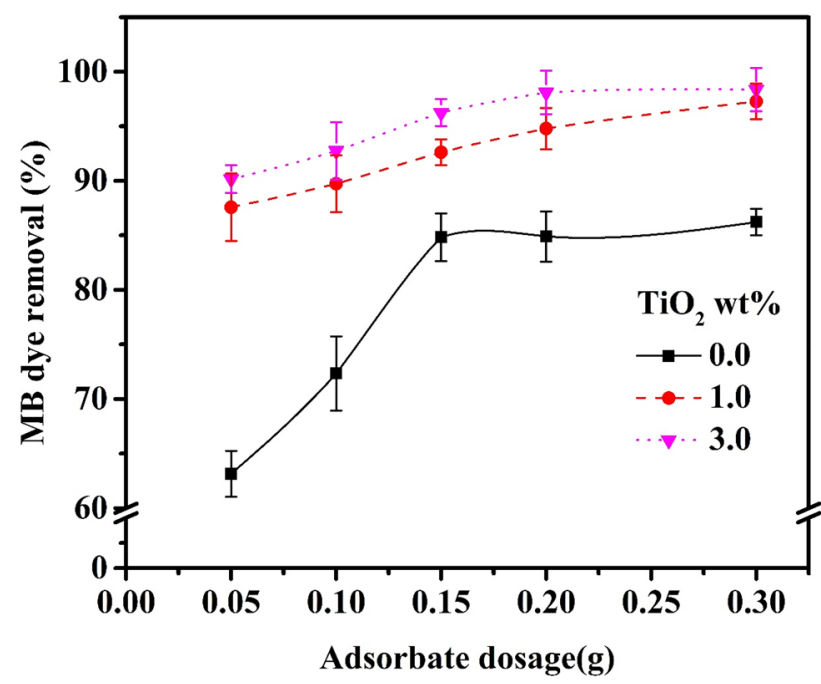

Fig. 7 The effect of the adsorbent dosage on the removal percentage of MB dye by CS-PAAc/ $/ \mathrm{TiO}_{2}$ nanocomposites at ambient temperature, initial dye concentration; $20 \mathrm{mg} / \mathrm{L}$ and contact time; $24 \mathrm{~h}$

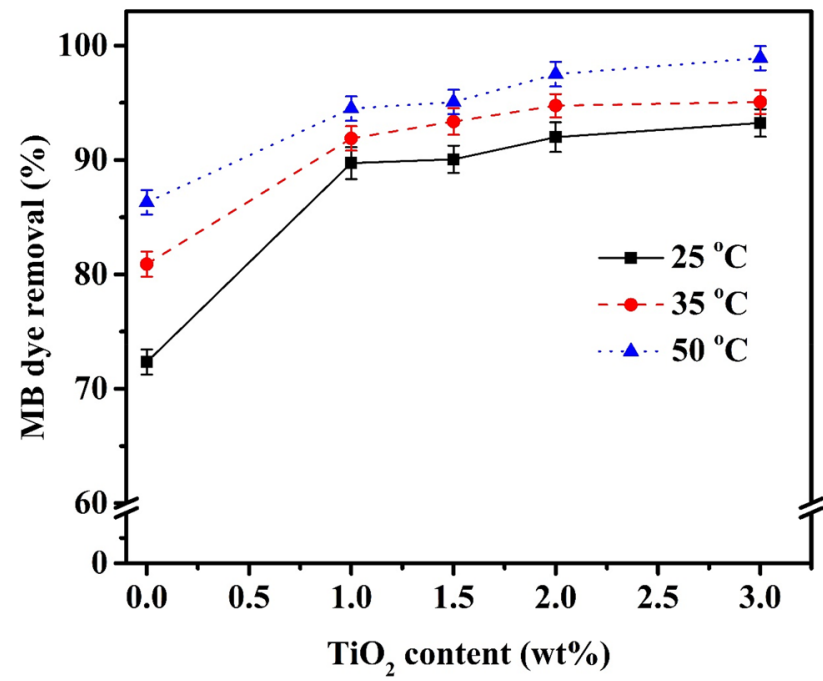

Fig. 8 The effect of $\mathrm{TiO}_{2}$ content (wt.\%) on the removal percentage of $\mathrm{MB}$ dye by $\mathrm{CS}-\mathrm{PAAC} / \mathrm{TiO}_{2}$ nanocomposites at different temperatures, initial dye concentration; $20 \mathrm{mg} / \mathrm{L}$ and contact time; $24 \mathrm{~h}$

of adsorbate. With increasing adsorbent dosage, more adsorption active sites are avaiable for adsorption of MB dye and consequently the dye removal raises. However, at higher dosage huge available functional groups on the adsorbent compared with the number of available dye molecules [44].

The influence of $\mathrm{TiO}_{2}$ content on the removal percentage of MB dye at different temperatures is shown in Fig. 8. It can be obtained that $\mathrm{TiO}_{2}$ does a remarkable increase in the removal parentage. The removal percentage of $\mathrm{MB}$ by CS-PAAc hydrogel $\left(\mathrm{TiO}_{2} ; 0.0 \mathrm{wt} . \%\right)$ is $73 \%$ at $25^{\circ} \mathrm{C}$ while it becomes $86 \%$ by using CS-PAAc/ $/ \mathrm{TiO}_{2}$ nanocomposite $\left(\mathrm{TiO}_{2} ; 1.0\right.$ wt.\%) at the same temperature. Above this $\mathrm{TiO}_{2}$ content value, a little increase in the removal percentage was observed with increasing $\mathrm{TiO}_{2}$ content in the nanocomposite.

On the other hand, an enhancement in the removal percentage was obtained by rising the temperature. This result indicated to that the adsorption reaction is endothermic.

The thermodynamics of adsorption of $M B$ dye onto CS-PAAC and CS-PAAC/TiO 2 nanocomposite hydrogels were analyzed by the thermodynamic parameters, such as Gibb's free energy change $(\Delta G)$, enthalpy change $(\Delta H)$, and entropy change $(\Delta S)$ that can be calculated by the following equations:

$\Delta G=-R T \ln K_{C}$

$K_{C}=\frac{Q_{e}}{C_{e}}$

$\ln K_{C}=\frac{\Delta S}{R}-\frac{\Delta H}{R T}$

where, $\mathrm{K}_{c}$ is the thermodynamics parameter, $\mathrm{T}$ is the absolute temperature $(K), R$ is the universal gas constant $\left(8.314 \mathrm{~J} \mathrm{~mol}^{-1} \mathrm{~K}^{-1}\right)$. The values of $\Delta \mathrm{H}$ and $\Delta \mathrm{S}$ can be obtained from the slope and intercept of the linear graph about $\operatorname{lnK}_{C}$ versus $1 / T$, as shown in Fig. 9, respectively as listed in Table 1.

For all samples, the values of $\Delta G$ at all investigated temperatures are negative during the adsorption process. This implies that the adsorption is thermodynamically

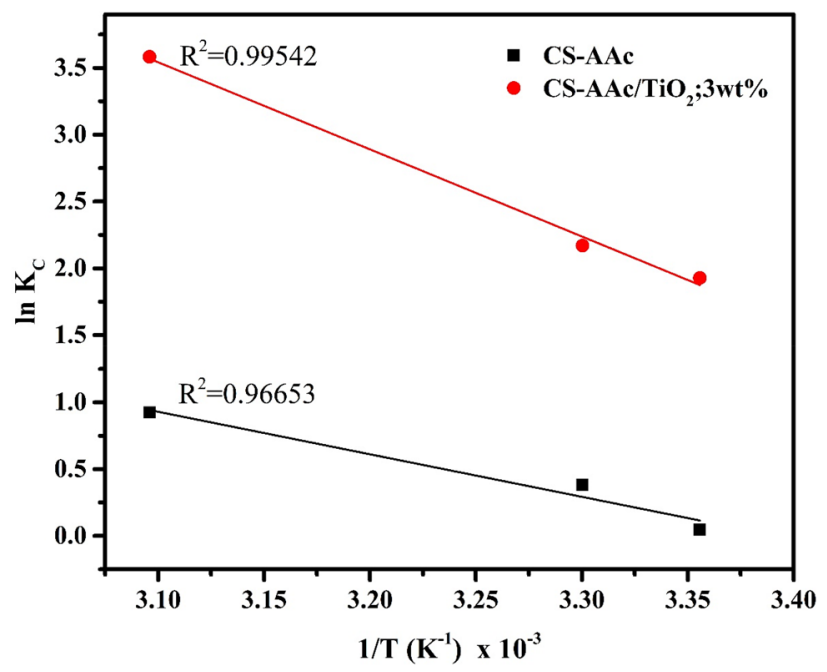

Fig. 9 Van't Hoff Plot for adsorption of MB dye onto CS-PAAC and CS-PAAC/TiO 
Table 1 Thermodynamic parameters of MB dye removal with CS$\mathrm{PAAC}$ and $\mathrm{CS}-\mathrm{PAAC} / \mathrm{TiO}_{2}$

\begin{tabular}{|c|c|c|c|c|}
\hline \multicolumn{5}{|c|}{ Thermodynamic parameters } \\
\hline Sample & $\mathrm{T}(\mathrm{K})$ & $\Delta \mathrm{G}\left(\mathrm{kJ} \cdot \mathrm{mol}^{-1}\right)$ & $\Delta \mathrm{S}\left(\mathrm{kJ} \cdot \mathrm{mol}^{-1} \mathrm{~K}^{-1}\right)$ & $\Delta \mathrm{H}\left(\mathrm{kJ} \cdot \mathrm{mol}^{-1}\right)$ \\
\hline \multirow[t]{3}{*}{ CS-PAAC } & 298 & -0.113 & \multirow[t]{3}{*}{0.089} & \multirow[t]{3}{*}{26.469} \\
\hline & 308 & -0.956 & & \\
\hline & 323 & -2.480 & & \\
\hline \multirow{3}{*}{$\begin{array}{c}\text { CS-PAAC/ } \\
\mathrm{TiO}_{2} ; 3 \\
\text { wt. } \%\end{array}$} & 298 & -4.77567 & \multirow[t]{3}{*}{0.198} & \multirow[t]{3}{*}{54.193} \\
\hline & 308 & -5.46654 & & \\
\hline & 323 & -9.62055 & & \\
\hline
\end{tabular}

favorable and spontaneous nature of the adsorption process. Moreover, the increase of the negative values of $\Delta G$ as the temperature increases indicated that the adsorption of $\mathrm{MB}$ onto $\mathrm{CS}-\mathrm{AAC}$ and $\mathrm{CS}-\mathrm{AAC} / \mathrm{TiO}_{2}$ nanocomposite hydrogel is more spontaneous at higher temperature. The positive values of $\Delta \mathrm{H}$ confirmed the physisorption process and the endothermic nature of adsorption. $\Delta S$ also has positive values demonstrated increasing the randomness at the solid-solution interface.

\section{Conclusions}

In the present study, CS-PAAc/ $\mathrm{TiO}_{2}$ nanocomposite hydrogel was prepared by gamma irradiation technique. Characterization and properties were investigated. It was found that XRD diffractograms of CS-PAAC/TiO ${ }_{2}$ nanocomposite hydrogels confirmed the presence of crystalline $\mathrm{TiO}_{2}$ nanoparticles in the nanocomposite hydrogels. The average particle size of $\mathrm{TiO}_{2}$ nanoparticles is estimated as; 5.8, 5.7, and $5.9 \mathrm{~nm}$ for $1.0,2.0$, and $3.0 \mathrm{wt} . \% \mathrm{TiO}_{2}$ content; respectively. The TGA results seem similar thermal behaviors and maximum thermal temperature in each stage of CS-PAAc/ $\mathrm{TiO}_{2}$ nanocomposite by varying the $\mathrm{TiO}_{2}$ content with very little change. However, the swelling percentage enhances nearly fourth times by adding $1 \mathrm{wt} . \% \mathrm{TiO}_{2}$ nanoparticle in the nanocomposite hydrogel compared with CS-PAAC hydrogel and there are further increases in the swelling percentage with increasing $\mathrm{TiO}_{2}$ content in the matrix. The adsorption characteristics of the prepared CS-PAAc/TiO2 nanocomposites were studied for removal of MB dye. It was obtained that the maximum removal percentage is obtained at $\mathrm{pH}=10.5$. The maximum adsorbent dosage for CS-PAAc/ $/ \mathrm{TiO}_{2}$ nanocomposites is $0.20 \mathrm{~g}$ and for CS-PAAC hydrogel is $0.15 \mathrm{~g}$ per liter of the adsorbate. The removal percentage of $\mathrm{MB}$ by CS-PAAC/TiO 2 nanocomposite is higher than CS-PAAc hydrogel however a little increase in the removal percentage was observed with increasing $\mathrm{TiO}_{2}$ content in the nanocomposite. The removal percentage is enhanced with rising the temperature this means the adsorption reaction is endothermic. This study revealed that the loading of $\mathrm{TiO}_{2}$ nanoparticles into the polymeric matrix of CS-PAAc does a remarkable increase in the removal parentage of $\mathrm{MB}$ dye from its aqueous solution.

\section{Compliance with ethical standards}

Conflict of interest The authors declare that they have no competing interests.

\section{References}

1. Meng J et al (2019) Preparation of aminated chitosan microspheres by one-pot method and their adsorption properties for dye wastewater. R Soc Open Sci 6(5):182226

2. Turan V et al (2018) Promoting the productivity and quality of brinjal aligned with heavy metals immobilization in a wastewater irrigated heavy metal polluted soil with biochar and chitosan. Ecotoxicol Environ Saf 161:409-419

3. Sarode $S$ et al (2019) Overview of wastewater treatment methods with special focus on biopolymer chitin-chitosan. Int J Biol Macromol 121:1086-1100

4. Chauhan $M$ et al (2020) Investigating the efficiency of alphaBismuth zinc oxide heterostructure composite/UV-LED in methylene blue dye removal and evaluation of its antimicrobial activity. Environ Res 180:108857

5. Su T et al (2019) Pullulan-derived nanocomposite hydrogels for wastewater remediation: synthesis and characterization. J Colloid Interface Sci 542:253-262

6. Yu S, Wang J, Cui J (2019) Preparation of a novel chitosanbased magnetic adsorbent CTS@SnO $\mathrm{OFe}_{3} \mathrm{O}_{4}$ for effective treatment of dye wastewater. Int J Biol Macromol. https://doi. org/10.1016/j.jibiomac.2019.11.194

7. Allafchian A, Mousavi ZS, Hosseini SS (2019) Application of cress seed musilage magnetic nanocomposites for removal of methylene blue dye from water. Int J Biol Macromol 136:199-208

8. Mohammadi AA, Dehghani MH, Mesdaghinia A, Yaghmaian K, Es'haghi Z (2019) Adsorptive removal of endocrine disrupting compounds from aqueous solutions using magnetic multi-wall carbon nanotubes modified with chitosan biopolymer based on response surface methodology: functionalization, kinetics, and isotherms studies. Int J Biol Macromol. https://doi.org/10.1016/j. ijbiomac.2019.11.065

9. Wang $\mathrm{W}$ et al (2019) $\mathrm{Pb}$ (II) removal from water using porous hydrogel of chitosan-2D montmorillonite. Int J Biol Macromol 128:85-93

10. Beck BH et al (2019) Antimicrobial activity of the biopolymer chitosan against Streptococcus iniae. J Fish Dis 42(3):371-377

11. Chen $S$ et al (2019) Core-shell biopolymer nanoparticles for co-delivery of curcumin and piperine: sequential electrostatic deposition of hyaluronic acid and chitosan shells on the zein core. ACS Appl Mater Interfaces 11(41):38103-38115

12. Wahid F et al (2017) Preparation, characterization and antibacterial applications of carboxymethyl chitosan/CuO nanocomposite hydrogels. Int J Biol Macromol 101:690-695

13. Arikal D, Kallingal A (2019) Photocatalytic degradation of azo and anthraquinone dye using $\mathrm{TiO}_{2} / \mathrm{MgO}$ nanocomposite immobilized chitosan hydrogels. Environ Technol. https://doi. org/10.1080/09593330.2019.1701094 
14. Rahman M et al (2018) Chitosan biopolymer promotes yield and stimulates accumulation of antioxidants in strawberry fruit. PLoS ONE 13(9):e0203769

15. Li C et al (2018) Fabrication of pure chitosan nanofibrous membranes as effective absorbent for dye removal. Int J Biol Macromol 106:768-774

16. Kong A et al (2018) A novel route for the removal of $\mathrm{Cu}(\mathrm{II})$ and $\mathrm{Ni}(\mathrm{II})$ ions via homogeneous adsorption by chitosan solution. J Clean Prod 192:801-808

17. Al Hosni AS, Pittman JK, Robson GD (2019) Microbial degradation of four biodegradable polymers in soil and compost demonstrating polycaprolactone as an ideal compostable plastic. Waste Manag 97:105-114

18. Franceschini $G$ (2019) Internal surgical use of biodegradable carbohydrate polymers: warning for a conscious and proper use of oxidized regenerated cellulose. Carbohydr Polym 216:213-216

19. Hodge J, Quint C (2019) The improvement of cell infiltration in an electrospun scaffold with multiple synthetic biodegradable polymers using sacrificial PEO microparticles. J Biomed Mater Res A 107(9):1954-1964

20. Abdulhameed AS, Mohammad A-T, Jawad AH (2019) Application of response surface methodology for enhanced synthesis of chitosan tripolyphosphate/ $\mathrm{TiO}_{2}$ nanocomposite and adsorption of reactive orange 16 dye. J Clean Prod 232:43-56

21. Lima AC et al (2019) Biodegradable polymers: an update on drug delivery in bone and cartilage diseases. Expert Opin Drug Deliv 16(8):795-813

22. Lu Y et al (2019) Immobilized Candida antarctica lipase B catalyzed synthesis of biodegradable polymers for biomedical applications. Biomater Sci 7(12):4963-4983

23. Nawi MA et al (2011) Photocatalytic-oxidation of solid state chitosan by immobilized bilayer assembly of $\mathrm{TiO}_{2}$-chitosan under a compact household fluorescent lamp irradiation. Carbohydr Polym 83(3):1146-1152

24. Nawi MA et al (2010) Adsorption of Reactive Red 4 by immobilized chitosan on glass plates: towards the design of immobilized $\mathrm{TiO}_{2}$-chitosan synergistic photocatalyst-adsorption bilayer system. Biochem Eng J 49(3):317-325

25. Nasef SM et al (2019) Gamma radiation-induced crosslinked composite membranes based on polyvinyl alcohol/chitosan/ $\mathrm{AgNO}_{3}$ /vitamin E for biomedical applications. Int J Biol Macromol 137:878-885

26. Maeng $M$ et al (2019) Everolimus-eluting versus biolimus-eluting stents with biodegradable polymers in unselected patients undergoing percutaneous coronary intervention: a randomized noninferiority trial with 1-year follow-up (SORT OUT VIII Trial). JACC Cardiovasc Interv 12(7):624-633

27. Ogueri KS, Allcock HR, Laurencin CT (2019) Generational biodegradable and regenerative polyphosphazene polymers and their blends with poly (lactic-co-glycolic acid). Prog Polym Sci, 98

28. Eivazzadeh-Keihan R, Radinekiyan F, Maleki A, Salimi Bani M, Hajizadeh Z, Asgharnasl S (2019) A novel biocompatible coreshell magnetic nanocomposite based on cross-linked chitosan hydrogels for in vitro hyperthermia of cancer therapy. Int J Biol Macromol 140:407-414. https://doi.org/10.1016/j.ijbio mac.2019.08.031
29. Jawad AH, Nawi MA (2012) Oxidation of crosslinked chitosanepichlorohydrine film and its application with $\mathrm{TiO}_{2}$ for phenol removal. Carbohydr Polym 90(1):87-94

30. Jayakumar R et al (2005) Graft copolymerized chitosan: present status and applications. Carbohydr Polym 62(2):142-158

31. Yu L et al (2004) A new hybrid nanocomposite prepared by graft copolymerization of butyl acrylate onto chitosan in the presence of organophilic montmorillonite. Radiat Phys Chem 69(6):467-471

32. Saleh AS et al (2018) Radiation grafting of acrylamide and maleic acid on chitosan and effective application for removal of Co(II) from aqueous solutions. Radiat Phys Chem 144:116-124

33. Nasef SM, Khozemy EE, Mahmoud GA (2019) Characterization and in vitro drug release properties of chitosan/acrylamide/gold nanocomposite prepared by gamma irradiation. Int J Polym Mater Polym Biomater 68(12):723-732

34. Mohamed AA, Mahmoud GA, EIDin ME, Saad E (2019) Synthesis and properties of (Gum acacia/polyacryamide/ $\mathrm{SiO}_{2}$ ) magnetic hydrogel nanocomposite prepared by gamma irradiation. Polym-Plast Technol Mater. https://doi.org/10.1080/25740 881.2019.1647240

35. Andreozzi M et al (2018) Treatment of saline produced water through photocatalysis using $\mathrm{rGO}^{-\mathrm{TiO}_{2}}$ nanocomposites. Catal Today 315:194-204

36. Shankar S et al (2014) PII: S0268-005X (14) 00438-X

37. Martins JT et al (2012) Synergistic effects between K-carrageenan and locust bean gum on physicochemical properties of edible films made thereof. Food Hydrocoll 29(2):280-289

38. Hegazy DE, Mahmoud GA (2014) Radiation synthesis and characterization of polyethylene oxide/chitosan-silver nanocomposite for biomedical applications. Arab J Nucl Sci Appl 47(2):1-14

39. Wojnárovits L, Földváry CM, Takács E (2010) Radiation-induced grafting of cellulose for adsorption of hazardous water pollutants: a review. Radiat Phys Chem 79(8):848-862

40. Rahim TNAT et al (2012) Water sorption characteristics of restorative dental composites immersed in acidic drinks. Dent Mater 28(6):e63-e70

41. Khairnar SD, Patil MR, Shrivastava VS (2018) Hydrothermally synthesized nanocrystalline $\mathrm{Nb}_{2} \mathrm{O}_{5}$ and its visible-light photocatalytic activity for the degradation of congo red and methylene blue. Iran J Catal 8(2):143-150

42. Mahmoud GA et al (2014) Radiation synthesis and characterization of starch-based hydrogels for removal of acid dye. StarchStärke 66(3-4):400-408

43. Mahmoud GA, Mohamed SF, Hassan HM (2015) Removal of methylene blue dye using biodegradable hydrogel and reusing in a secondary adsorption process. Desalin Water Treat 54(10):2765-2776

44. Khozamy E et al (2019) Implementation of carboxymethyl cellulose/acrylic acid/titanium dioxide nanocomposite hydrogel in remediation of $\mathrm{Cd}$ (II), $\mathrm{Zn}$ (II) and $\mathrm{Pb}$ (II) for water treatment application. Egypt J Chem 62(10):1785-1798

Publisher's Note Springer Nature remains neutral with regard to jurisdictional claims in published maps and institutional affiliations. 